\title{
Iron-Catalyzed Halogen Exchange of Trifluoromethyl Arenes
}

\author{
Andreas Dorian, a Emily J. Landgreen, ${ }^{b}$ Hayley R. Petras, ${ }^{b}$ James J. Shepherd, b Florence J. Williams*b
}

(a) University of Alberta. Edmonton, Alberta, Canada

(b) University of lowa. lowa City, lowa, USA. florence-williams@uiowa.edu

Supporting information (DOE designs, calculations, procedures, and characterization) provided in a separate supplementary document also available on ChemRxiv.

\begin{abstract}
We report the facile production of $\mathrm{ArCF}_{2} \mathrm{X}$ and $\mathrm{ArCX}_{3}$ from $\mathrm{ArCF}_{3}$ using catalytic iron(III)halides, which constitutes the first ironcatalyzed halogen exchange for non-aromatic $C-F$ bonds. Theoretical calculations suggest this transformation likely involves direct activation of $\mathrm{C}-\mathrm{F}$ bonds by iron coordination. $\mathrm{ArCX}_{3}$ and $\mathrm{ArCF}_{2} \mathrm{X}$ products of the reaction are synthetically valuable due to their diversification potential. In particular, bromo-, chloro-, and iododifluoromethyl arenes $\left(\mathrm{ArCF}_{2} \mathrm{Br}, \mathrm{ArCF}_{2} \mathrm{Cl}, \mathrm{ArCF}_{2}\right.$ l, respectively) provide access to a myriad of difluoromethyl arene derivatives $\left(\mathrm{ArCF}_{2} \mathrm{R}\right)$. To optimize for mono-halogen exchange, a statistical method called Design of Experiment was used. Optimized parameters were successfully applied to electron rich and electron deficient aromatic substrates, and were applied to the late stage diversification of flufenoxuron, a commercial insecticide.
\end{abstract}

C-F bonds impart desirable features to a molecule, such as chemical inertness and increased lipophilicity. ${ }^{[1]}$ As such, fluorinated moieties continue to play a critical role in the modern pharmaceutical, agrochemical and materials chemistry fields, and are of longstanding synthetic interest to organic chemists. ${ }^{[2]} \mathrm{A}$ prominent example, the trifluoromethyl group $\left(\mathrm{CF}_{3}\right)$ is present in $24 \%$ of drugs globally approved in $2019 .{ }^{[3]}$

The selective conversion of $\mathrm{C}-\mathrm{F}$ bonds to $\mathrm{C}-\mathrm{H}$ or $\mathrm{C}-\mathrm{C}$ bonds in polyfluorinated molecules has enjoyed increased focus as a strategy to access challenging fluorination patterns. ${ }^{[4]} \mathrm{A}$ related transformation is the conversion to higher halide $\mathrm{C}-\mathrm{X}$ bonds $(\mathrm{X}=$ $\mathrm{Cl}, \mathrm{Br}, \mathrm{I}$ ), through halogen-exchange (halex) reactions. ${ }^{[5]}{ }^{[6]}$ These larger halides are versatile synthetic handles, with heightened reactivity over the parent fluoride.

Halex reactions on fluorinated substrates are typically performed with stoichiometric early valent metal halides $\left(\mathrm{TiX}_{4}, \mathrm{MoCl}_{5}\right)$, or $\mathrm{p}$ block metalloid halides $\left(\mathrm{BX}_{3}, \mathrm{AlX}_{3}, \mathrm{R}_{3} \mathrm{SiX}\right){ }^{[7]}$ These halide reagents provide the necessary thermodynamic drive through formation of a strong fluoride bond (e.g. SiF $166 \mathrm{kcal} / \mathrm{mol}_{4} \mathrm{BF}_{3} 170 \mathrm{kcal} / \mathrm{mol}$ ). ${ }^{\left[{ }^{[]}\right.}$ However, additional catalysts are necessary in order to avoid high temperatures and long reaction times.

Iron, being a low-cost high abundance metal, has been surprisingly absent in catalytic defluorination development. The potential of iron catalysis in this field is nevertheless exemplified in enzymes such as Horseradish peroxidase (HRP), Methane monooxygenase (MMO) and Cytochrome P450s (CYPs), all employing iron-based catalytic motifs, which perform catalytic defluorination along with oxygenation. ${ }^{[9]}$ In fact, to our knowledge only one precedent exists for iron-catalyzed halogen exchange of $\mathrm{C}-\mathrm{F}$ bonds: Igumnov and coworkers observed chlorination of perfluorinated benzenes at high temperatures $\left(120^{\circ} \mathrm{C}\right)$ with yields up to $21 \% .^{[10]}$ The following work constitutes the first example of iron-catalyzed halogen exchange of non-aromatic $\mathrm{C}-\mathrm{F}$ bonds, and to our knowledge the first halogen exchange with mechanistic evidence for iron coordination and activation of the C-F bond directly. This method was applied and optimized for medicinally relevant $\mathrm{ArCF}_{3}$ substrates.

We explored a variety of halophilic Lewis acidic transition metal complexes in the presence of boron tribromide and trifluoromethyl ( $m$-fluoro)benzene 1a. In the absence of a catalyst, the known background halex reaction between boron tribromide and trifluoro-

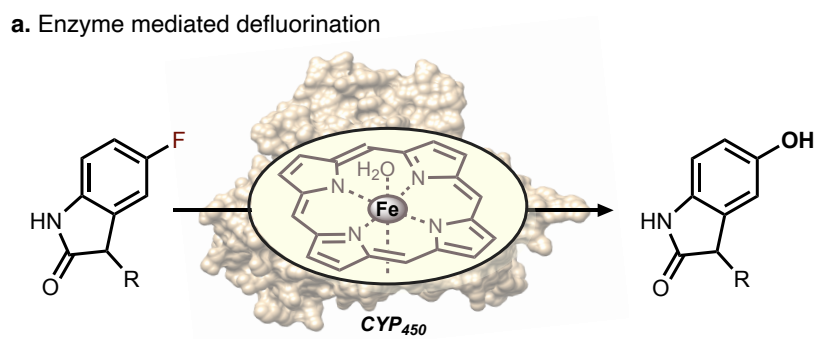

b. Aryl C-F halex (Igumnov et al.)

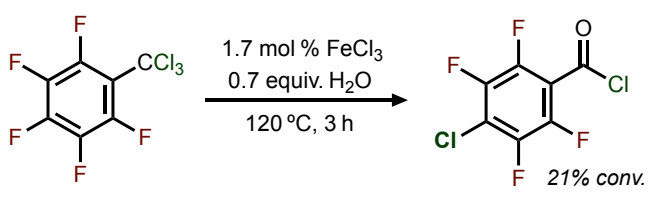

c. Aliphatic C-F halex (this work)

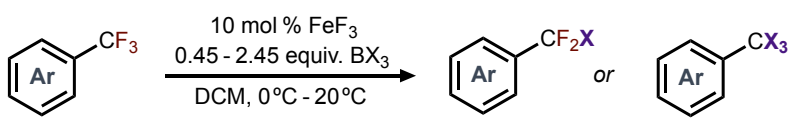

Figure 1. a) representative example of a $\mathrm{CYP}_{450}$ enzyme-catalyzed defluorination and concurrent hydroxylation. ${ }^{[9 b]} \mathrm{CYP}_{450}$ contains an ironporphyrin active site. b) prior iron-catalyzed aryl C-F halogen-exchange. ${ }^{[10]} \mathrm{C}$ ) iron-catalyzed benzylic C-F halogen exchange described in this paper.

methyl arenes occurs slowly to provide compound $\mathbf{2 a}$ at $7 \%$ conversion (Table 1, entry 1). ${ }^{[6 b]}$ While silver $(I)$, copper $(I)$, iron(0) and iron (II) showed no improvements on C-F exchange efficiencies (entries 2-5), iron(III) and gallium(III) compounds accelerated the halex process significantly (entries 6-10), generating tribrominated product $4 \mathrm{a}$ in $83-91 \%$. Interestingly, the identity of the halide on the iron(III) center did not affect the reaction significantly, aside from a small amount of chlorinated product formed when iron(III)chloride $\left(\mathrm{FeC}_{13}\right)$ was used (entry 6), with bromination still predominant.

Ensuing investigations were performed with iron(III)fluoride. Solvent selection proved important (Table 1, entries 11-13), possibly due to solubility differences for the iron catalyst. In nitromethane, coordination of solvent with $\mathrm{BBr}_{3}$ (confirmed by ${ }^{11} \mathrm{~B}$ NMR) is suspected to mitigate reactivity. 
Table 1. Screening Investigations

\begin{tabular}{|c|c|c|c|c|c|c|}
\hline & $V^{F}$ & $\begin{array}{r}5 \% \text { cataly } \\
1 \text { equiv. hal } \\
\text { solvent }\end{array}$ & In & $3 r$ & $X_{3 a}^{\mathrm{Fr}}$ & ${ }_{\mathrm{Ar}}^{\mathrm{Br}} \mathrm{X}_{\mathbf{4 a}}^{\mathrm{Br}}$ \\
\hline entry & catalyst & halide & solvent & $2 a(\%)^{a}$ & $4 a(\%)^{a}$ & $\mathbf{C}-\mathbf{F}_{\text {total }}(\%)^{b}$ \\
\hline 1 & - & $\mathrm{BBr}_{3}$ & DCM & 7 & nd. & 7 \\
\hline 2 & $\mathrm{AgBr}$ & $\mathrm{BBr}_{3}$ & $\mathrm{DCM}$ & 8 & nd. & 9 \\
\hline 3 & Cul & $\mathrm{BBr}_{3}$ & $\mathrm{DCM}$ & 7 & nd. & 8 \\
\hline 4 & $\mathrm{Fe}(\mathrm{CO})_{5}$ & $\mathrm{BBr}_{3}$ & DCM & 7 & nd. & 8 \\
\hline 5 & $\mathrm{FeCl}_{2}$ & $\mathrm{BBr}_{3}$ & $\mathrm{DCM}$ & 6 & nd. & 7 \\
\hline 6 & $\mathrm{FeCl}_{3}$ & $\mathrm{BBr}_{3}$ & DCM & 4 & 89 & 272 \\
\hline 7 & $\mathrm{FeBr}_{3}$ & $\mathrm{BBr}_{3}$ & DCM & 5 & 83 & 256 \\
\hline 8 & $\mathrm{FeF}_{3}$ & $\mathrm{BBr}_{3}$ & $\mathrm{DCM}$ & 5 & 83 & 255 \\
\hline 9 & $\mathrm{Fe}(\mathrm{OTf})_{3}$ & $\mathrm{BBr}_{3}$ & $\mathrm{DCM}$ & tr. & 91 & 273 \\
\hline 10 & $\mathrm{Ga}(\mathrm{OTf})_{3}$ & $\mathrm{BBr}_{3}$ & $\mathrm{DCM}$ & tr. & 83 & 249 \\
\hline 11 & $\mathrm{FeF}_{3}$ & $\mathrm{BBr}_{3}$ & heptane & tr. & nd. & tr. \\
\hline 12 & $\mathrm{FeF}_{3}$ & $\mathrm{BBr}_{3}$ & $\mathrm{PhCl}$ & 14 & tr. & 27 \\
\hline 13 & $\mathrm{FeF}_{3}$ & $\mathrm{BBr}_{3}$ & $\mathrm{MeNO}_{2}$ & $n d$. & $n d$. & $n d$. \\
\hline $14^{c}$ & $\mathrm{FeF}_{3}$ & $\mathrm{Me}_{2} \mathrm{BBr}$ & DCM & 21 & 35 & 128 \\
\hline $15^{c}$ & $\mathrm{FeF}_{3}$ & (cat)BBr & DCM & tr. & nd. & tr. \\
\hline $16^{d}$ & $\mathrm{FeF}_{3}$ & $\mathrm{BCl}_{3}$ & DCM & 6 & $n d$. & 6 \\
\hline $17^{e}$ & $\mathrm{FeF}_{3}$ & $\mathrm{Bl}_{3}$ & DCM & 5 & $n d$. & 5 \\
\hline $18^{f}$ & $\mathrm{FeF}_{3}$ & $\mathrm{BBr}_{3}$ & DCM & nd. & 92 & 277 \\
\hline $19^{g}$ & $\mathrm{FeF}_{3}$ & $\mathrm{BBr}_{3}$ & $\mathrm{DCM}$ & 12 & $n d$. & 15 \\
\hline
\end{tabular}

Reactions performed at $1.0 \mathrm{mmol}$ scale, $20^{\circ} \mathrm{C}, 5$ hours, $0.2 \mathrm{M}$ concentration. Compound 3 a was trace in all entries $(<3 \%$ conversion). cat $=$ catechol. $n d$. = not detected. $t r .=$ trace. $\left[\right.$ a] Conversions determined by ${ }^{19} \mathrm{~F} \mathrm{NMR}$ (relative to 4 fluorotoluene internal standard). [b] $\mathrm{C}-\mathrm{F}_{\text {total }}$ refers to the molar percentage of $\mathrm{C}$ $\mathrm{F}$ bonds converted to $\mathrm{C}-\mathrm{X}$ bonds, relative to starting moles of $\mathrm{ArCF}_{3}$. [c] 3 equiv. $\mathrm{R}_{2} \mathrm{BBr}$ used. [d] $\mathrm{ArCF}_{2} \mathrm{Cl}$ formed instead of 2a. [e] $\mathrm{ArCF}_{2}$ l formed instead of $\mathbf{2 a}$. [f] 3 equiv. $\mathrm{BBr}_{3}$ used, $12 \mathrm{~h}$ time. [g] Performed at $-10^{\circ} \mathrm{C}$.

To our satisfaction, alternative boryl halides were also competent in the halex reaction (entries 14-17), including boron trichloride $\left(\mathrm{BCl}_{3}\right)$ and boron triiodide $\left(\mathrm{Bl}_{3}\right)$, which afforded $\mathrm{ArCF}_{2} \mathrm{Cl}$ or $\mathrm{ArCF}_{2} \mathrm{I}$, respectively (entries 16-17), although these reactions were slow relative to those with boron tribromide. Conversion to 4 a was optimized by using excess $\mathrm{BBr}_{3}$ and extending the reaction time to 12 hours (entry 18). Tribromomethyl arenes can be used in a number of synthetic applications, including conversion to carboxylic acids/esters, alkynes and alkenes, and to generate heterocycles. ${ }^{[11]}\left[{ }^{[6 g]}\right.$ Accordingly, we envision this operationallysimple method using common reagents to be of significant utility, given the prevalence of trifluoromethyl groups in high profile compounds.

However, we were also intrigued by the potential to optimize the reaction for a single halogen-exchange, generating compound $\mathbf{2 a}$. In addition to unique intrinsic properties, such as increased capacity for halogen bonding, $\mathrm{ArCF}_{2} \mathrm{X}$ compounds are common intermediates for redox and cross-coupling reactions that generate a range of high value difluoro derivatives $\left(\mathrm{ArCF}_{2} \mathrm{R}\right.$, Figure 2) ${ }^{[12][13]}$

Optimizing a single halex on a trifluoromethyl center is a challenge, as the $\mathrm{C}-\mathrm{F}$ bond strength decreases with each fluorine removal. ${ }^{[14]}$ Encouragingly, lowering of the reaction temperature increased conversion to $\mathrm{ArCF}_{2} \mathrm{Br}$ (2a) relative to the $\mathrm{ArCBr}_{3}$ (4a) (entry 19). This observation indicated that, despite the unfavorable

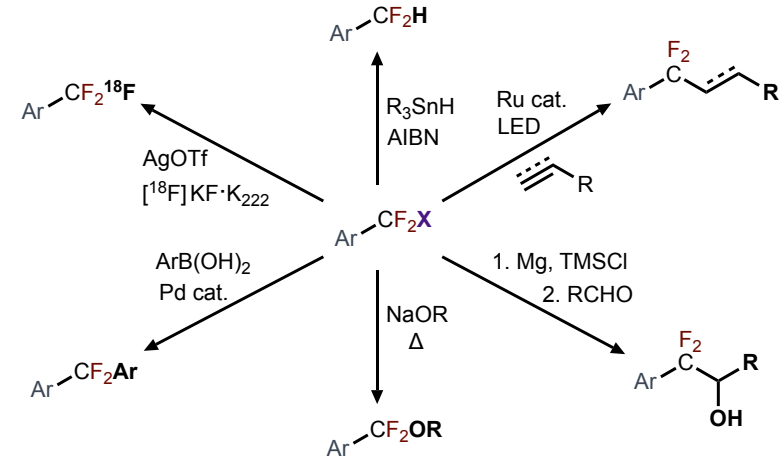

Figure 2. Transformations of $\mathrm{ArCF}_{2} \mathrm{X}(\mathrm{X}=\mathrm{Br}, \mathrm{Cl})$ reported in the literature. ${ }^{[12]}$

thermodynamic profile for selective mono halogen exchange, appropriate reaction tuning could provide synthetically viable amounts of the $\mathrm{ArCF}_{2} \mathrm{Br}$ product.

This complexity led us to use the statistical method Design of Experiments (DOE) for refined optimization. DOE uses regression analysis to generate a mathematical model of a selected reaction outcome as a function of defined reaction parameters (variables). ${ }^{[15]}$ The relative importance of each parameter, as well as interaction effects between parameters is determined by analysis of variance (ANOVA).

We first performed a 5-variable fractional factorial DOE to evaluate the main linear effects of the following variables/parameters on conversion to $\mathrm{ArCF}_{2} \mathrm{Br}$ : temperature, time, solvent molarity, $\mathrm{FeF}_{3}$ loading, and $\mathrm{BBr}_{3}$ equivalents (see $\mathrm{SI}$ for details). This model indicated the $\mathrm{FeF}_{3}$ loading parameter was not significant (likely due to its solubility limit in dichloromethane).

Therefore, $\mathrm{FeF}_{3}$ loading was fixed at $10 \%$ in the subsequent DOE, which utilized a response surface design, a more predicative model that accounts for non-linear effects. Evaluation of data normalcy, $R^{2}$ fit, a test for over-fitting $\left(R^{2}\right.$ adjusted), a test for predictive

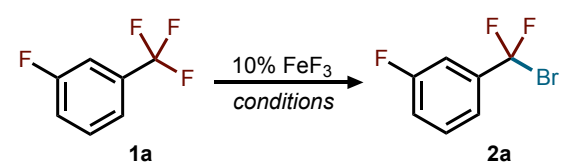

(T) -25 to $0^{\circ} \mathrm{C}$

(t) 8 to $16 \mathrm{~h}$

(B) 0.7 to 1.7 equiv. $\mathrm{BBr}_{3}$

(M) 0.12 to $0.28 \mathrm{M} \mathrm{DCM}$

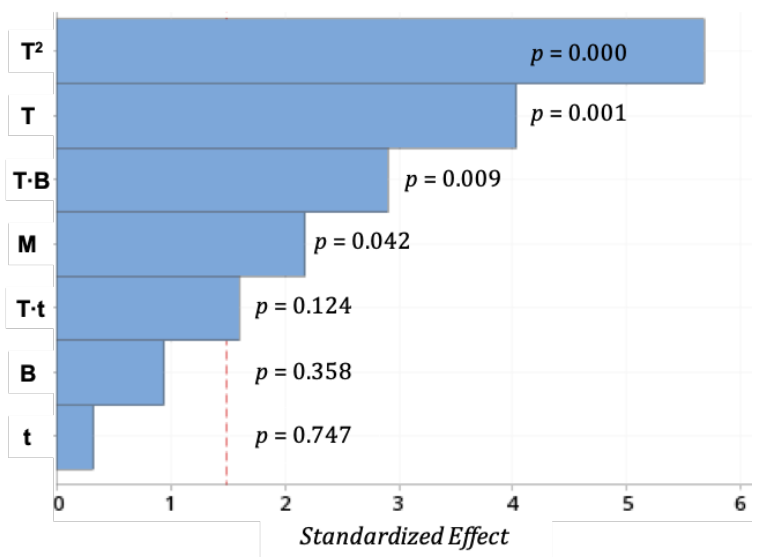

Figure 3. Pareto chart with added $p$-values for a response surface model of $2 a$ formation. The red dotted line is a reference corresponding to the standardized effect $t$-value determined by significance level $\alpha=0.15$, where $\alpha$ is the probability of obtaining a false positive on a statistical test. 
power ( $R^{2}$ predicted), and analysis of error versus reaction order (test for systematic experimental error), indicated that we had a wellfitted model for $\mathrm{ArCF}_{2} \mathrm{Br}$ conversion. We also performed test reactions to confirm that experimental conversion values were comparable to those predicted by the model (See SI).

The significance of each variable in the DOE model is shown the Pareto chart depicted in Figure 3. Such information can reflect mechanistic nuance. Temperature was found to be strongly correlated with $\mathrm{ArCF}_{2} \mathrm{Br}$ conversion and has a significant interaction effect with $\mathrm{BBr}_{3}$.
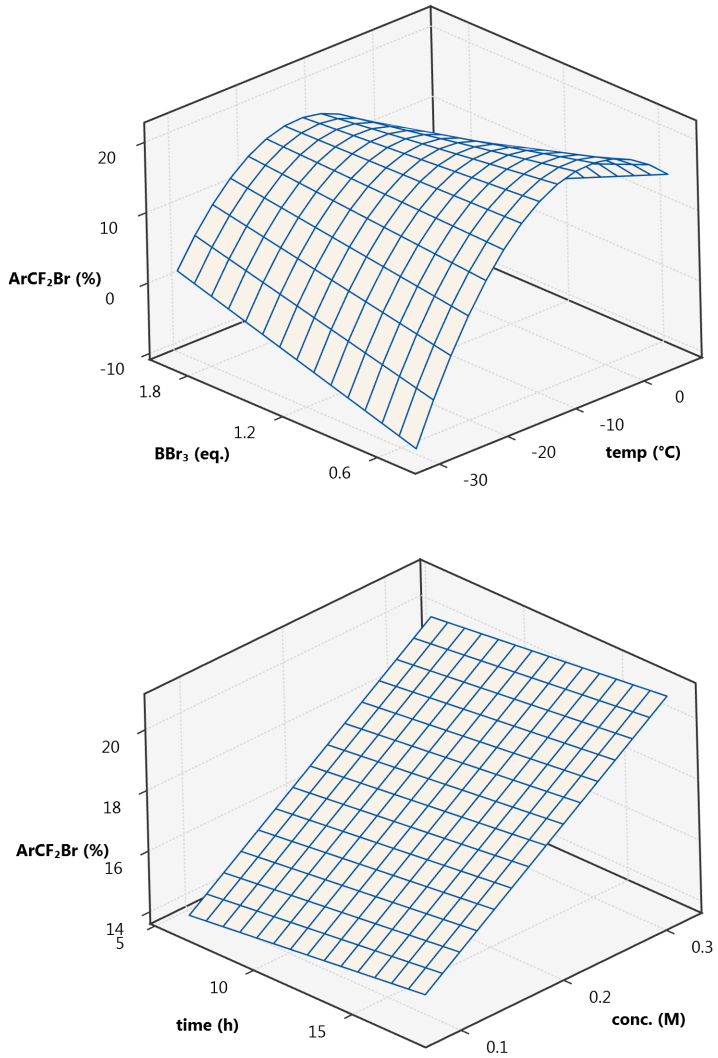

Figure 4. Surface plots from the DOE model. [Above] $\mathrm{ArCF}_{2} \mathrm{Br}$ conversion as a function of $\mathrm{BBr}_{3}$ equivalents and temperature (constants: time $=12 \mathrm{~h}$, concentration $=0.2 \mathrm{M}$ ). [Below] $\mathrm{ArCF}_{2} \mathrm{Br}$ conversion as a function of time and concentration (constants: $\mathrm{BBr}_{3}=1.2$ equivalents, temperature $=-12.5^{\circ} \mathrm{C}$ ).

Figure 4 shows the parabolic shape of the temperature effect, with a maximum at $-3{ }^{\circ} \mathrm{C}$, and the benefit of low $\mathrm{BBr}_{3}$ equivalents (maximium at 0.45 equiv.). On the other hand, time has a relatively small effect, as shown by the very shallow slope in Figure 3 (see $\mathrm{SI}$ for other surface plots). These results suggest that optimal conversion is more complex than identifying a time point where a statistical mixture of products favors $\mathrm{ArCF}_{2} \mathrm{Br}$. In such a scenario, time would be highly significant to the model. The DOE model identified optimal conditions corresponding to a maximum $\mathrm{ArCF}_{2} \mathrm{X}$ conversion of $25 \%$. Evaluation of these conditions experimentally, resulted in $28 \%$ conversion to $\mathrm{ArCF}_{2} \mathrm{X} \mathbf{2 a}$, slightly outperforming the model (Scheme 1).

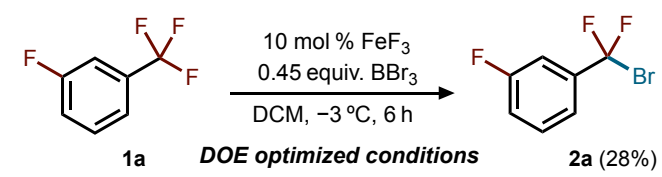

Scheme 1. DOE optimized conditions for the synthesis of $\mathrm{ArCF}_{2} \mathrm{Br}$

Given optimized reaction parameters for meta-fluoro substrate 1a, we sought to apply conditions favoring $\mathrm{ArCF}_{2} \mathrm{X}$ formation to a selection of substrates (Scheme 2). The reaction was observed to progress more rapidly with electron rich aromatic complexes, which was easily compensated for with shorter reaction times. Gratifyingly, similar conversions to the desired $\mathrm{ArCF}_{2} \mathrm{Br}$ could be obtained for most substrates examined. For compounds with coordinating Lewis basic functionalities, additional equivalents of $\mathrm{BBr}_{3}$ were necessary to account for competing coordination preferences $(\mathbf{2} \mathbf{i}, \mathbf{2} \mathbf{j}, \mathbf{2} \mathbf{2 k})$. Substitution at ortho, meta, and para positions, including halides, alkyl, and hydroxy groups were all well tolerated. Isolation of $\mathrm{ArCF}_{2} \mathrm{X}$ was achieved using reverse-phase HPLC, whereas small molecule substrates are reported as conversions, due to volatility affecting isolated yields. No evidence was observed of styrene derivatives or Friedel-Crafts alkylation arising from iron(III) activation of the alkyl bromide side chain with substrate $\mathbf{1 h}$. Chlorination was also achieved using similar conditions (compound $\mathbf{2 c}$ ).

To our delight, phosphine $\mathbf{1 i}$ was converted to desymmetrized mono-brominated compound $\mathbf{2} \mathbf{i}$ in $17 \%$ isolated yield, despite 9 different fluorines which can participate in the halex reaction. Further, commercial insecticide flufenoxuron (1k), was converted to mono-brominated derivative $\mathbf{2 k}$ in $21 \%$ conversion and $13 \%$ isolated yield (Scheme 3 ).

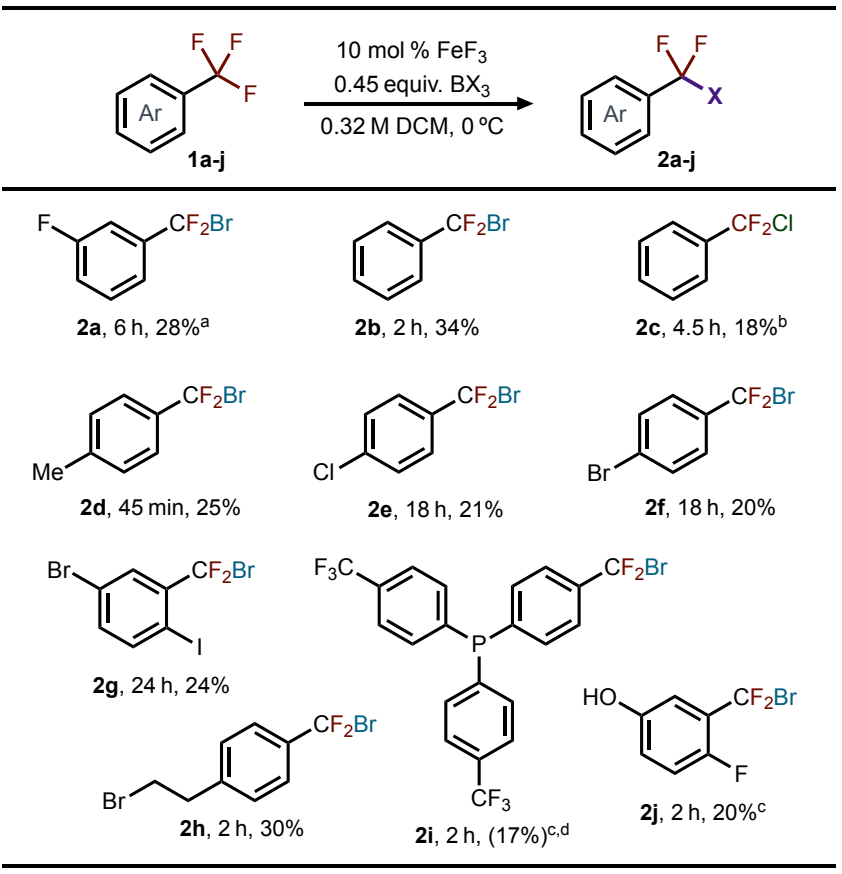

Scheme 2. Scope investigations for the mono-halex of trifluoromethyl arenes ( $0.40 \mathrm{mmol}$ scale). Conversions determined by ${ }^{19} \mathrm{~F}$ NMR (relative to 4 fluorotoluene internal standard), isolated yields in parentheses. [a] Performed at $-3^{\circ} \mathrm{C}$. [b] $0.2 \mathrm{M} \mathrm{NO}_{2} \mathrm{Me} / \mathrm{DCM}(2: 1), 0.45$ equiv. $\mathrm{FeCl}_{3}, 1.2$ equiv. $\mathrm{BCl}_{3}, 10^{\circ} \mathrm{C}$. [c] $\mathrm{Fe}(\mathrm{OTf})_{3}$ in place of $\mathrm{FeF}_{3}$. [d] 1.45 equivalents $\mathrm{BBr}_{3}$ used. 


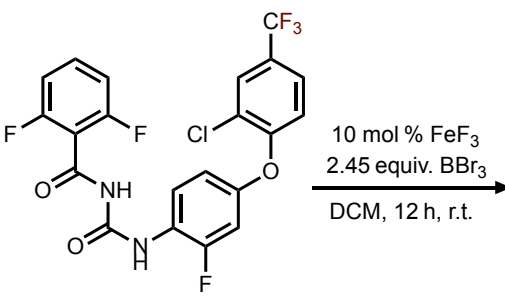

$1 \mathrm{k}$

Flufenoxuron

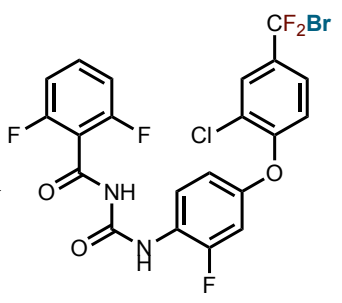

2k

Scheme 3. Halogen exchange with a commercial insecticide flufenoxuron.

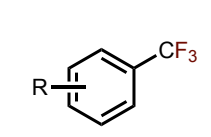

1a

1e<smiles>COc1ccc(C(F)(F)F)cc1</smiles>

11

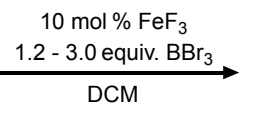

$\mathrm{R}={ }^{m} \mathrm{~F}, 20^{\circ} \mathrm{C}, 12 \mathrm{~h}:$

$\mathrm{R}={ }^{P} \mathrm{Me}, 0^{\circ} \mathrm{C}, 5 \mathrm{~h}$ :

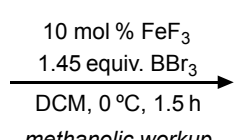

methanolic workup

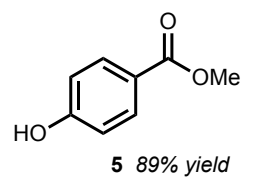

Scheme 4. Yields of tribromomethyl arenes produced using triple-halex.

Further, substrates $\mathbf{1 a}, \mathbf{1 e}$ and $\mathbf{1 l}$ were converted to tribromomethylarenes $\mathbf{4 a}, \mathbf{4 e}$, and compound $\mathbf{5}$ with excellent isolated yields (85-89\%). Compound $\mathbf{5}$ was generated from an methanolic workup, resulting from rapid hydrolysis/methanolysis of the tribromomethyl group. These substrates demonstrate that electron deficient and electron rich arenes are competent in triple halogen exchange of benzylic trifluoromethyl groups.

Theoretical calculations were used to investigate the mechanistic role of the iron catalyst. Using unrestricted Kohn-Sham density functional theory B3LYP/6-31G ${ }^{* *},{ }^{[16]}$ coordination energies between $\mathrm{PhCF}_{3} \mathbf{1 b}, \mathrm{BCl}_{3}$, and $\mathrm{FeCl}_{3}$ were determined in dimeric and trimeric orientations (see SI for a complete library of calculated complexes). Since the halex exchange works similarly well with $\mathrm{BCl}_{3}$ as $\mathrm{BBr}_{3}$, a $\mathrm{BCl}_{3}$ reaction to introduce chloride was chosen. The background halex reaction with $\mathrm{BCl}_{3}$ (without iron) is slow enough to be non-competitive.

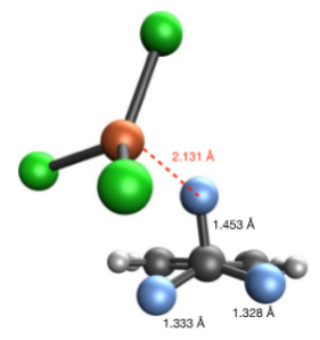

Figure 5. Computed geometries \& bond lengths for $\mathrm{FeCl}_{3}$ coordination to $\mathrm{PhCF}_{3}$

The lowest dimeric coordination energy observed was between $\mathrm{PhCF}_{3}$ and $\mathrm{FeCl}_{3}$ at $-14.65 \mathrm{kcal} / \mathrm{mol}$ (Figure 5). This interaction is predicted to stretch the coordinated $\mathrm{C}-\mathrm{F}$ bond by approximately $0.1 \AA$. In contrast, the binding energy of $\mathrm{PhCF}_{3}$ and $\mathrm{BCl}_{3}$ is much less significant at $-1.34 \mathrm{kcal} / \mathrm{mol} .{ }^{19} \mathrm{~F}$ NMR experiments support these calculations. The fluorine signal in $\mathrm{PhCF}_{3}$ is shifted downfield by $2.5 \mathrm{ppm}$ in the presence of $\mathrm{FeCl}_{3}$, whereas $\mathrm{BCl}_{3}$ only elicits a downfield shift of $0.2 \mathrm{ppm}$.

The lowest energy trimers $\left(\mathrm{PhCF}_{3}, \mathrm{BCl}_{3}, \mathrm{FeCl}_{3}\right.$ ) have interactions dominated by $\mathrm{PhCF}_{3}$ and $\mathrm{FeCl}_{3}$ binding; the lowest energy trimer is calculated to be at $-15.35 \mathrm{kcal} / \mathrm{mol}$ relative to the monomers (See SI for details). Therefore, while iron activation of the boron trichloride remains a valid mechanistic possibility, calculations and NMR shift experiments suggest direct interaction with the $\mathrm{PhCF}_{3}$ substrate is energetically favorable and weakens the $\mathrm{C}-\mathrm{F}$ bond.

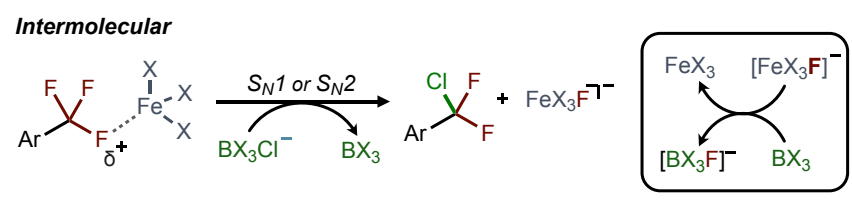

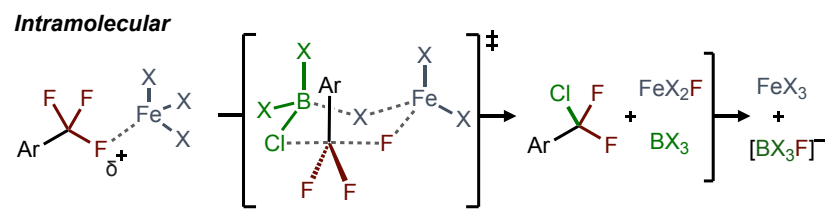

Figure 6. Plausible mechanisms for the halex reaction.

Figure 6 shows plausible mechanisms based on these data, where iron initiates activation of the $\mathrm{C}-\mathrm{F}$ bond, facilitating nucleophilic substitution, and ultimately abstracting the fluoride. The nucleophilic chloride is likely delivered from a boron halide complex, as the identity of the boron halide reagent determines the major halogen exchange product. Subsequent transfer of the fluoride to the boron center is required for the process to be exergonic overall (for the first $\mathrm{Cl}$ exchange: $-5.17 \mathrm{kcal} / \mathrm{mol}$ B3LYP/6-31G**,$-7.56 \mathrm{kcal} / \mathrm{mol} \operatorname{CCSD}(\mathrm{T}) / \mathrm{CBS}),{ }^{[17]}$ and this is corroborated by experimental observations of gas evolution $\left(\mathrm{BF}_{3}\right)$ and the loss of the ${ }^{11} \mathrm{~B}$ NMR signal in the reaction mixture.

In conclusion, we have demonstrated that ferric halides catalyze halogen-exchange between trifluoromethyl arenes and boron halides. While early conditions favor full exchange of benzylic fluorides, providing $\mathrm{ArCX}_{3}$ products, $\mathrm{DOE}$ analyses provided conditions that maximize mono-exchange to generate $\mathrm{ArCF}_{2} \mathrm{X}$ products in synthetically viable yields. The tunable halex reaction was also shown to produce the analogous chlorodifluoromethyl and iododifluoromethyl groups. Scope investigations demonstrated successful application to electron-deficient and electron-rich arenes, with good functional group tolerance. The reaction is also eminently practical, using inexpensive, readily available reagents and run at easily maintained temperatures.

Significantly, mechanistic insight from computational analyses suggest that ferric halides are likely direct activators of the $\mathrm{C}-\mathrm{F}$ bond, which has important implications for future $\mathrm{C}-\mathrm{F}$ activation methodology development. Further investigations into the mechanistic role of the iron catalyst in halex reactions are ongoing. 


\section{Acknowledgements}

The authors thank Dr. Pamela Tadross, of Merck Industries, for her feedback and advice regarding Design of Experiments.

This work was primarily supported by NSERC RGPIN-201604843, the ACS Petroleum Research Fund PRF 59191-ND1, and the Canadian Foundation for Innovation IOF-34997 (FW and AD: experimental work and DOE). Additional support (AD) is acknowledged from Dr. Ralf Schirrmacher, through NSERC RGPIN-2019-04481. Electronic structure calculations (JS, EL, and HRP) were supported by the University of lowa.

\section{References}

[1] D. O'Hagan, Chem. Soc. Rev. 2008, 37, 308-319.

[2] a.) E. P. Gillis, K. J. Eastman, M. D. Hill, D. J. Donnelly, N. A Meanwell, J. Med. Chem. 2015, 58, 8315-8359; b.) R. Berger, G. Resnati, P. Metrangolo, E. Weber, J. Hulliger, Chem. Soc. Rev. 2011 40, 3496-3508.

[3] a.) M. Inoue, Y. Sumii, N. Shibata, ACS Omega 2020, 5, 1063310640; b.) C. Alonso, E. Martinez de Marigorta, G. Rubiales, F. Palacios, Chem. Rev. 2015, 115, 1847-1935.

[4] a.) T. Fujita, K. Fuchibe, J. Ichikawa, Angew. Chem. Int. Ed. 2019 58, 390-402; b.) F. Jaroschik, Chem. Euro. J. 2018, 24, 14572 14582; c.) J. D. Hamel, J. F. Paquin, Chem. Commun. 2018, 54, 10224-10239; d.) T. Ahrens, J. Kohlmann, M. Ahrens, T. Braun, Chem. Rev. 2015, 115, 931-972; e.) H. Amii, K. Uneyama, Chem. Rev. 2009, 109, 2119-2183.

[5] a.) K. K. K. Goh, A. Sinha, C. Fraser, R. D. Young, RSC Adv. 2016, 6, 42708-42712; b.) M. Janjetovic, A. Ekebergh, A. M. Traff, G Hilmersson, Org. Lett. 2016, 18, 2804-2807; c.) A. M. Traff, M. Janjetovic, L. Ta, G. Hilmersson, Angew. Chem. Int. Ed. 2013, 52, 12073-12076; d.) Y. Mizukami, Z. Song, T. Takahashi, Org. Lett. 2015, 17, 5942-5945; e.) K. Matsubara, T. Ishibashi, Y. Koga, Org. Lett. 2009, 11, 1765-1768; f.) J. Terao, S. A. Begum, Y. Shinohara, M. Tomita, Y. Naitoh, N. Kambe, Chem. Commun. 2007, 855-857; g.) M. Namavari, N. Satyamurthy, J. R. Barrio, J. F. Chem. 1995, 72, 89-93; h.) G. A. Olah, S. C. Narang, L. D. Field, J. Org. Chem. 1981, 46, 3727-3728; i.) J. San Filippo Jr., A. F. Sowinski, L. J. Romano, J. Org. Chem. 1975, 40, 3295-3296.
[6] a.) D. Mandal, R. Gupta, A. K. Jaiswal, R. D. Young, J. Am. Chem Soc. 2020, 142, 2572-2578; b.) G. K. S. Prakash, J. Hu, J. Simon, D. R. Bellew, G. A. Olah, J. F. Chem. 2004, 125, 595-601; c.) F. Dankert, H. L. Deubner, M. Müller, M. R. Buchner, F. Kraus, C. von Hänisch, Z. Anorg. Allg. Chem. 2020, 646, 1501-1507; d.) A. L. Henne, M. S. Newman, J. Am. Chem. Soc. 1938; e.) J. Riera, J. Castaiier, J. Carilla, A. Robert, Tet. Lett. 1989, 30; f.) R. K. Ramchandani, R. D. Wakharkar, A. Sudalai, Tet. Lett. 1996, 37, 4063-4064; g.) M. Ikeda, T. Matsuzawa, T. Morita, T. Hosoya, S. Yoshida, Chem. Eur. J. 2020, 26, 12333-12337.

[7] T. Stahl, H. F. T. Klare, M. Oestreich, ACS Catal. 2013, 3, 1578-1587

[8] a.) D. J. Grant, D. A. Dixon, J. Phys. Chem. A 2009, 113, 777-787; b.) R. Walsh, J. Chem. Soc., Faraday Trans. 1 1983, 79, 2233-2248.

[9] a.) Y. Wang, A. Liu, Chem. Soc. Rev. 2020, 49, 4906-4925; b.) G. M. Amaya, R. Durandis, D. S. Bourgeois, J. A. Perkins, A. A. Abouda, K. J. Wines, M. Mohamud, S. A. Starks, R. N. Daniels, K. D. Jackson, Chem. Res. Toxicol. 2018, 31, 570-584.

[10] A. I. Shipilov, L. A. Kolpashchikova, S. M. Igumnov, Russ. J. Org. Chem. 2003, 39, 975-978.

[11] a.) Q. Sun, X. Yu, M. Bao, M. Liu, J. Pan, Z. Zha, L. Cai, H. Ma, C. Yuan, X. Qiu, W. Xu, Angew. Chem. Int. Ed. 2018, 57, 4035-4038; b.) H. Liu, S.-i. Kondo, N. Takeda, M. Unno, Eur. J. Inorg. Chem. 2009, 1317-1319.

[12] a.) M. Yoshida, M. Morinaga, M. Iyoda, J. F. Chem. 1994; b.) S. Sumino, M. Uno, T. Fukuyama, I. Ryu, M. Matsuura, A. Yamamoto, Y. Kishikawa, J. Org. Chem. 2017, 82, 5469-5474; c.) J. Guidotti, C. Wakselman, F. Metz, M. Tordeux, Synlett 2004, 1759-1762; d.) J. Guidotti, V. Schanen, M. Tordeux, C. Wakselman, J. F. Chem. 2005, 126, 443-447; e.) J.-W. Gu, W.-H. Guo, X. Zhang, Org. Chem. Front. 2015, 2, 38-41; f.) S. Verhoog, L. Pfeifer, T. Khotavivattana, S. Calderwood, T. Collier, K. Wheelhouse, M. Tredwell, V. Gouverneur, Synlett 2015, 27, 25-28.

[13] a.) X. J. Tang, Z. Zhang, W. R. Dolbier, Jr., Chem. Eur. J. 2015, 21, 18961-18965; b.) Z. Zhang, X. Tang, W. R. Dolbier, Jr., Org. Lett. 2015, 17, 4401-4403; c.) H. Jiang, W. Lu, K. Yang, G. Ma, M. Xu, J. Li, J. Yao, W. Wan, H. Deng, S. Wu, S. Zhu, J. Hao, Chem. Eur. J. 2014, 20, 10084-10092.

[14] G. Glockler, J. Phys. Chem. 1959, 63, 828-832.

[15] S. A. Weissman, N. G. Anderson, Org. Process Res. Dev. 2015, 19, 1605-1633

[16] a.) A. D. Becke, J. Chem. Phys. 1993, 98, 1372-1377; b.) V. A. Rassolov, M. A. Ratner, J. A. Pople, P. C. Redfern, L. A. Curtiss, J. Comput. Chem. 2001, 22, 976-984.

[17] R. J. Bartlett, M. Musiał, Rev. Mod. Phys. 2007, 79, 291-352. 